\title{
QUESTÃO PENITENCIÁRIA E \\ ENCARCERAMENTO FEMININO
}

PENITENTIARY ISSUE AND FEMALE IMPRISONMENT

\section{Valeska Berman Machado'}

RECEBIDO EM: 01/06/2017 | APROVADO EM: 22/07/2017

DOI: $10.5902 / 2317175827471$

\section{RESUMO}

Este ensaio teórico tem como objetivo abarcar e problematizar elementos basilares para a fundamentação teórica da questão penitenciária e do encarceramento feminino, esclarecendo noções importantes em relação ao cenário, não unicamente contemporâneo, mas também histórico que envolve a questão penitenciária. O texto está dividido em dois blocos: o primeiro traz uma reflexão sobre a trajetória da pena de prisão e a constituição de uma questão penitenciária, o segundo tensiona a relação entre mulher, cárcere e prisão.

Palavras-chave: Questão penitenciária; Encarceramento feminino; Mulher; prisão.

\footnotetext{
1 Possui graduação em Serviço Social pelo Centro Universitário Franciscano (2011) e Residência Multiprofissional com ênfase em Saúde Mental pela Universidade Federal de Santa Maria (2015) e Mestrado em Política Social pela Universidade Católica de Pelotas (2015). Atualmente é Professora Substituta na Universidade Federal de Santa Maria e Coordenadora do Trabalho Social no Serviço Nacional de Aprendizagem Comercial - Santa Maria/RS. Tem experiência na área de Sociologia, com ênfase em encarceramento feminino, atuando principalmente nos seguintes temas: serviço social, capitalismo, relações sociais, políticas públicas, saúde mental, homofobia, gênero, encarceramento feminino e política de habitação. E-mail: bermanvaleska@ gmail.com.
} 


\begin{abstract}
In this theoretical essay, we aim to encompass and problematize basic elements for the theoretical foundation of the penitentiary issue and female imprisonment, clarifying important notions regarding the scenario, not only contemporary but also historical that involves the penitentiary issue. The text is divided in two blocks: the first one reflects on the trajectory of the prison sentence and the constitution of a penitentiary issue, the second one stresses the relationship between woman, jail and prison.
\end{abstract}

Keywords: Penitentiary issue; Female incarceration; Woman; prison.

\title{
1 Introdução
}

O presente ensaio é fruto de uma pesquisa teórica norteada pela questão penitenciária, a qual é entendida como ponto de intersecção entre políticas públicas, sociais, de segurança e criminais. Seu objeto constitui-se por um viés de gênero frente ao incremento do encarceramento feminino. Conforme Freire (2009), podemos observar uma gradual transição em termos de políticas de segurança: de um paradigma de Segurança Nacional, característico do período de governos militares, quando o foco era representado estritamente em relação às ameaças aos interesses nacionais (na figura do inimigo), avançamos a um paradigma de Segurança Pública, que se pauta na ameaça à integridade das pessoas e do patrimônio, e, por fim, assistimos atualmente à emergência de um terceiro paradigma: o da Segurança Cidadã, respaldada na Constituição Federal de 88. A Segurança Cidadã ainda caminha a passos lentos para sua total efetivação, pois esbarra em visões institucionais distantes dos elementos das políticas sociais, como se estas fossem alheias à esfera da segurança, repercutindo ainda uma perspectiva operacional-repressiva.

\section{Questão Penitenciária}

Conforme Michel Foucault ([1975]2004)², durante todo o século XVIII, dentro e fora do judiciário, na prática penal cotidiana e nas instituições, foi possível observar a implementação de uma nova estratégia de exercício do poder e do castigo. Com o objetivo principal de "não punir menos, mas punir melhor, [...] com uma severidade atenuada, [...] inserir mais profundamente no corpo social o poder de punir" (FOUCAULT, 2004, p. 70), o direito de punir descolou-se da vingança do soberano à defesa da sociedade.

Ora, eis o problema: depois de bem pouco tempo, a detenção se tornou a forma essencial de castigo. No Código Penal [Francês] de 1810, entre a morte e as multas, ela ocupa, sob um certo

2 Em relação aos autores clássicos, como Foucault, indicamos, na primeira citação, entre colchetes o ano original da obra, seguido do ano da edição utilizada como fonte bibliográfica. As utilizações seguintes indicarão apenas o ano desta última. 
número de formas, quase todo o campo das punições possíveis (FOUCAULT, 2004, p. 95).

Seguindo Foucault (2004), a duração da pena só tem sentido em sua relação com a correção e com a utilização econômica dos criminosos corrigidos; se observarmos o modelo inglês, ainda é acrescido o isolamento como fator essencial. A prisão assemelha-se a uma fábrica.

Quanto aos instrumentos utilizados, não são mais jogos de representação que são reforçados e que se faz circular; mas formas de coerção, esquemas de limitação aplicados e repetidos. Exercícios, e não sinais: horários, distribuição do tempo, movimentos obrigatórios, atividades regulares, meditação solitária, trabalho em comum, silêncio, aplicação, respeito, bons hábitos; E finalmente, o que se procura reconstruir nessa técnica de correção não é tanto o sujeito de direito, que se encontra preso nos interesses fundamentais do pacto social: é o sujeito obediente, o indivíduo sujeito a hábitos, regras, ordens, uma autoridade que se exerce continuamente sobre ele e em torno dele, e que ele deve deixar funcionar automaticamente nele (FOUCAULT, 2004, p. 106).

No decorrer dos séculos XVII e XVIII, a disciplina tornou-se a fórmula geral da dominação, uma política de coerção na qual o corpo é trabalhado por um viés de manipulação, calculando elementos como gestos e comportamentos (FOUCAULT, 2004).

O corpo humano entra numa maquinaria de poder que o esquadrinha, o desarticula e o recompõe. Uma "anatomia política", que é também igualmente uma "mecânica do poder", está nascendo; ela define como se pode ter domínio sobre o corpo dos outros, não simplesmente para que façam o que se quer, mas para que operem como se quer, com as técnicas, segundo a rapidez e a eficácia que se determina. A disciplina fabrica assim corpos submissos e exercitados, corpos "dóceis". A disciplina aumenta as forças do corpo (em termos econômicos de utilidade) e diminui essas mesmas forças (em termos políticos de obediência) (FOUCAULT, 2004, p. 119).

Foucault (2004) ainda salienta que a articulação entre corpo e objeto é claramente definida pela disciplina, explicitando as relações que o corpo deve manter com o objeto que o manipula e estabelecendo a influência de um sobre o outro.

Em resumo, pode-se dizer que a disciplina produz, a partir dos corpos que controla, quatro tipos de individualidade, ou antes uma individualidade dotada de quatro características: é celular (pelo jogo da repartição especial), é orgânica (pela codificação das atividades), é genética (pela acumulação do tempo), é combinatória (pela composição das forças). E, para tanto, utiliza quatro grandes técnicas: constrói quadros; prescreve manobras; 
impõe exercícios; enfim para realizar a combinação das forças, organiza "táticas". A tática, arte de construir com os corpos localizados, atividades codificadas e as aptidões formadas, apareIhos em que o produto das diferentes forças se encontra majorado por sua combinação calculada é sem dúvida a forma mais elevada da prática disciplinar (FOUCAULT, 2004, p. 141).

É possível analisar que, na conjuntura do século XVIII, estavam arraigados fundamentos gerais de toda prática disciplinar, desde o controle e o exercício dos corpos individuais até a utilização das forças específicas às multiplicidades mais complexas. Nesse sentido, Foucault (2004, p. 146) define que:

O aparelho disciplinar perfeito capacitaria um único olhar tudo ver perfeitamente. Um ponto central seria ao mesmo tempo fonte de luz que iluminasse todas as coisas, e lugar de convergência para tudo o que deve ser sabido: olho perfeito a que nada escapa e centro de direção ao qual todos os olhares convergem.

A prisão, para o autor (2004), nada mais é do que o reflexo das concepções acerca do poder de punir, adotadas em diferentes momentos da história da sociedade.

Contudo, os pioneiros na análise das relações entre punição e estrutura social são Georg Rusche e Otto Kirchheimer ([1939]2004), os quais conectaram as motivações do encarceramento, como método de punição, ao desenvolvimento da sociedade industrial. Alessandro De Giorgi, comentando as abordagens desses autores - conhecidos como referenciais no que se denomina Economia Política da Punição - sintetiza:

A prisão se consolida então como dispositivo orientado à produção e à reprodução de uma subjetividade operária. Deve-se forjar, na penitenciária, uma nova categoria de indivíduos, indivíduos predispostos a obedecer, seguir ordens e respeitar ritmos de trabalho regulares, e, sobretudo que estejam em condições de interiorizar a nova concepção capitalista do tempo como medida do valor e do espaço como delimitação do ambiente de trabalho. Delineiam-se aqui os contornos de uma economia política do corpo, de uma tecnologia do controle disciplinar que age sobre o corpo para governá-lo enquanto produtor de mais-valia e que, juntamente com outros corpos "cientificamente" organizados, torna-se capital (DE GIORGI, 2006, p. 44-45).

Conforme Rusche e Kirchheimer (2004), as medidas punitivas não estariam somente ligadas a métodos de repressão, supressão de liberdade ou exclusão. Essas medidas apresentavam-se sob um viés positivo e "útil", no sentido de que deveriam sustentar uma economia servil, pois teriam o papel de arrecadar uma mão de obra suplementar, ou seja, de construir uma escravidão "civil". Isso justifica a intenção das ações profissionalizantes para os pre- 
sos, para que, posteriormente, estes pudessem ocupar funções nas indústrias, alimentando o crescimento do capitalismo, considerando-se que o corpo dos presos só se tornaria útil se fosse, ao mesmo tempo, produtivo e submisso.

$\mathrm{Na}$ abordagem de Foucault (2004), o sistema punitivo seria um subsistema social garantidor do sistema de produção da vida, ou seja, das práticas punitivas consubstanciais, o que se configura como uma economia política do corpo que visa docilizar os presos e aproveitar suas forças corporais.

A prisão seria definida como um instrumento de gestão da criminalidade e não de supressão desta, partindo do princípio de que a disciplina é a própria (micro)física do poder, exercida por meio do controle e da sujeição deste, levando em conta os métodos de "adestramento", como a vigilância hierárquica e a sanção normatizadora (FOUCAULT, 2004), não considerando as funções (re)habilitação do apenado.

Quanto a esse sentido inicial conferido à prisão, na análise de sua trajetória histórica bem como de seus redimensionamentos, David Garland (2008) apresenta uma visão mais contemporânea sobre o sistema penitenciário, abordando, em sua obra, os anos 1960, nos quais o previdenciarismo penal surgiu como tendência de maior força dentre os grupos envolvidos na justiça criminal, assim como dentre os funcionários do governo, os profissionais do trabaIho social e as elites liberais.

A idéia de "progresso na reforma penal" era convencional e inteligível, porque capturava o senso de implementação gradual de um programa progressista cujos postulados eram amplamente aceitos e respeitados. [...] As práticas penais-previdenciárias também estavam inseridas num contexto mais amplo. Sua estrutura básica e funcionamento estavam enraizadas nas diferenciadas práticas institucionais da sociedade moderna, e seus programas e ideologias de trabalho eram elementos integrantes do Estado do bem-estar do pós-guerra, bem como de sua democracia social (GARLAND, 2008, p. 95).

Para Garland (2008), o previdenciarismo penal desenvolveu-se dos anos 1950 aos anos 1960, sendo, pois, nos anos 1970 que se estabeleceu como política. O principal dogma do previdenciarismo era o princípio de medidas penais materializadas, sempre que possível, em intervenções reabilitadoras ao invés de em punição retributiva.

Evidentemente, o nível de compromisso com os aspectos previdenciários do previdenciarismo penal era bastante variado - tanto ao longo das jurisdições locais quanto no seio das instituições, agências e grupos que compunham o sistema. Fiscais do livramento condicional, funcionários dos juizados de crianças e adolescentes, supervisores de reformatórios, diretores de prisões, pesquisadores de criminologia, funcionários públicos experientes e os psicólogos, psiquiatras e pedagogos do sistema eram comumente mais entusiasmados do que os agentes penitenciários de carreira, 
policiais e promotores de Justiça. Tampouco estava o sistema livre de restrições e de conflitos (GARLAND, 2008, p. 107).

Desse modo, "discursos e práticas que compunham o campo penal-previdenciário foram erguidos sobre certas premissas sociopolíticas fundamentais" (GARLAND, 2008, p. 109), as quais se dividiam entre os liberais, que sustentavam a ideia de "que o crime era um sintoma de desigualdade: que criminosos deviam ser compreendidos antes de julgados; que não se pode permitir à polícia a violação dos direitos dos suspeitos" (GARLAND, 2008, p. 108), e os conservadores, que defendiam "o efeito intimidatório das sentenças duras e a necessidade de condenações a penas longas, assim como da pena de morte" (GARLAND, 2008, p. 108). Ambos os grupos se vinculavam ao previdenciarismo penal, porém, cada um pautado por seus próprios princípios.

\begin{abstract}
Princípios penais-previdenciários tendiam a trabalhar contra o uso do encarceramento, considerando que a prisão era amplamente vista como contraproducente, do ponto de vista da reforma do indivíduo. Regimes de custódia especializados - reformatórios para jovens infratores, prisões-escola, estabelecimentos correcionais etc. - eram preferidos às prisões tradicionais, e a preterição do encarceramento em favor de medidas comunitárias se tornou um esforço constante dos reformadores correcionalistas. No enquadramento penal-previdenciário, a reabilitação não era apenas um elemento entre outros (GARLAND,2008, p. 104).
\end{abstract}

Garland (2008) define como estilo penal-previdenciário a dinâmica de constante progressão ao direcionamento correcionalista de reabilitação, ao bem-estar e ao saber criminológico especializado no controle do crime. Porém, essas tensões se davam em meio de um consenso profissional sob o qual o controle do crime deveria operar como uma forte onda de compartilhamento de objetivos e valores que seriam a base da justiça criminal.

Assim, o sistema moderno de captura, acusação e punição de violadores da lei penal se tornou especializado e, ao mesmo tempo, diferenciado, constituindo parte do aparato do Estado moderno. Ao longo do tempo, veio a ser administrado por burocracias profissionais, por instituições úteis, por leis e por sanções, especialmente designadas para este propósito. Estes processos históricos de diferenciação, estatização, burocratização e profissionalização são características fundamentais do que podemos chamar de "modernização" do controle do crime e da justiça criminal (GARLAND, 2008, p. 97).

A partir do final de 1970 e 1980, o previdenciarismo nos Estados Unidos da América (EUA) e na Europa entrou em declínio, emergindo um novo momento da questão penitenciária, no qual o Estado é punitivo e não se preocupa tanto com a correção. 
Esse declínio foi proporcionado pela falta de evidências ou provas de que a prisão desempenha, com sucesso, os papéis atribuídos a ela (BAUMAN, 1999), como também pela forte preocupação com a acentuada aceleração do encarceramento, visto que muitos segmentos populares, vez ou outra, ameaçam a ordem social, sendo a prisão o único método dado como eficiente para a neutralização da ameaça e da ansiedade pública.

Cresce rapidamente em quase todos os países o número de pessoas na prisão ou que esperam prováveis sentenças de prisão. Em quase toda a parte a rede de prisões está se ampliando intensamente. Os gastos orçamentários do Estado com as "forças da lei e da ordem", principalmente os efeitos policiais e os serviços penitenciários, crescem em todo o planeta (BAUMAN, 1999, p. 122).

Conforme Loïc Wacquant (2003), o encarceramento tornou-se uma verdadeira indústria e, como tal, lucrativa. Utilizando-se da lógica do "tudo penal", a indústria de aparatos penais privados motivou-se, e as administrações públicas perpetuamente carentes voltaram-se a estas para melhor rentabilizar os orçamentos.

Wacquant (2003) ainda completa que "o inchamento explosivo das populações carcerárias, [...] a eliminação dos programas de trabalho e de educação no interior das penitenciárias, a multiplicação dos instrumentos de vigilância" somente dão conta de controlar populações perigosas, ao contrário do que em seu discurso coloca como "reabilitar".

[...] e, na falta disso, estocá-los em separado para remediar a incúria dos serviços sociais que não se mostram nem desejosos nem capazes de tomá-los sob sua responsabilidade. A ascensão do Estado penal americano responde assim não à ascensão da criminalidade, que permaneceu constante durante todo este período, mas ao deslocamento social provocado pelo desengajamento do Estado caritativo. E ela mesma tende a se tornar a sua própria justificativa, na medida em que seus efeitos criminógenos contribuem pesadamente para a insegurança e para a violência que deveria remediar (WACQUANT, 2003, p. 32-33).

Não obstante isso, o sistema prisional, em especial no Brasil, sempre se constituiu de forma problemática e contraditória entre as previsões legais e as realidades institucionais e organizacionais de execução penal e assumindo a questão penitenciária sob a perspectiva de que ela se:

[...] constitui e se manifesta por meio de expressões teóricas e concretas (políticas, institucionais e práticas) dos paradoxos e das contradições entre os discursos e as promessas acerca do castigo penal pretensamente civilizado (a privação da liberdade) e a realidade de sua execução pelos Estados modernos evidencia-se contemporaneamente nas intersecções das esferas da política penal, criminal e social e por meio de dinâmicas de complementaridade e/ou de substituições (CHIES, 2013, p. 16). 
Frente a isso, Chies (2013) sugere duas linhas básicas de enfrentamento: a cognitivo-explicativa, caracterizada pelo desvelamento exploratório das expressões identificáveis da questão penitenciária; e a cognitivo-combativa, que avança no nível propositivo e de suplante dos paradoxos da mesma questão. A segunda subdivide-se em outros dois eixos, sendo estes: o abolicionista, cujo horizonte se dá pela suplantação das penalidades de reclusão; e o da redução de danos, a qual busca, por meio de melhorias do sistema penitenciário, atenuar o sofrimento dos cidadãos reclusos.

Nesse sentido, optamos por trabalhar com a abordagem de redução de danos, pois, enquanto ainda for inviável a ruptura histórica da pena de prisão, não podemos permanecer de braços cruzados, sabendo que dia após dia cidadãos são condenados à privação de liberdade como método punitivo e correcionalista.

\section{Mulher e prisão}

Faz-se necessário entrelaçar a lógica da punição posta no sistema penal com a falta de visibilidade do incremento do encarceramento feminino, o qual advém, muitas vezes, da repressão definida como uma linguagem que constitui o domínio imaginável do gênero, tendo em vista os limites da discussão desse assunto no meio público.

\footnotetext{
Os limites da análise discursiva do gênero pressupõem e definem por antecipação as possibilidades das configurações imagináveis e realizáveis do gênero na cultura. Isso não quer dizer que toda e qualquer possibilidade de gênero seja facultada, mas que as fronteiras analíticas sugerem os limites de uma experiência discursivamente condicionada. Tais limites se estabelecem sempre nos termos de um discurso cultural hegemônico, baseado em estruturas binárias que se apresentam como linguagem da racionalidade universal (BUTLER, 2008, p. 28).
}

Chies (2008) sugere que, desde Pandora, ícone feminino da tradição grega, e de Eva, das crenças judaico-cristãs, a mulher é vista como sinônimo de pecado, uma vez que incita o comportamento desviante, fora dos padrões aceitos socialmente. Nessa perspectiva, podemos observar que as questões de gênero estão muito presentes em nossa cultura, inclusive no sistema carcerário brasileiro. Este se configura como um cenário androcêntrico, pautado por uma teoria sexista, pensada e executada em prol do masculino. Na maioria das vezes, não considera as peculiaridades pertinentes aos indivíduos femininos.

Podemos acompanhar os pensamentos de Julita Lemgruber $(1999$, p. 4) quando afirma que "os anos 70 foram caracterizados por uma mudança significativa nos estudos sobre a criminalidade feminina". Historicamente, podemos dizer que alguns questionamentos foram dados como falhos e outros apontavam emergência nas discussões. 
Primeiramente, a partir da "teoria dos papéis". Os teóricos que desenvolveram esta abordagem negam as explicações anteriores baseadas em fatores biológicos ou psíquicos e procuram centrar sua atenção na diferente socialização e nas diferentes reações sociais ao crime entre indivíduos do sexo masculino e feminino (LEMGRUBER, 1999, p. 4).

Lemgruber faz uso das teorias de Hoffman e Bustamante para caracterizar que as influências culturais, inclusive as quais relaciona os tipos de crimes cometidos pelas mulheres à sua posição de subalternidade. Estas, ensinadas a se portarem de maneira passiva e não agressiva, acabavam por se envolver em crimes menos violentos e, quando participam destes, executavam papéis secundários.

Continuando, Lemgruber contempla-nos com as ideias de Freud, o qual simboliza o crime feminino como rebelião contra o papel biológico das mulheres, porém, sendo violentamente condenadas por duas vezes: legalmente, através de um processo criminal; e, socialmente, consideradas biológica e sexualmente anormais.

Porém, algumas teorias foram questionadas, dentre elas a "teoria dos papéis", pois não analisa a origem social dos papéis, não discute a divisão do trabalho e, muito menos, contempla em termos históricos, econômicos e culturais a inferioridade posta no feminino. Por fim, não esclarece o motivo que leva essas mulheres a cometerem crimes.

Diversos autores sustentam que o crescimento das taxas de criminalidade feminina está relacionado com o início dos Movimentos de Libertação da Mulher. O argumento desses estudiosos passa pela afirmação de que os crimes cometidos por mulheres estão se tornando mais masculinos e particularmente mais violentos. Dizem, ainda, que à medida em que as mulheres procuram igualar-se aos homens, tendem ao crime com maior freqüência (LEMGRUBER, 1999, p. 5).

Tais críticos, entretanto, não consideram que a relação causal entre o aumento da criminalidade feminina e o Movimento de Libertação contempla as mudanças estruturais e econômicas na vida das mulheres, não buscando unicamente igualdade entre os sexos, mas a própria sobrevivência no mercado de trabalho, principalmente se considerarmos os momentos de crise ou de expansão econômica.

Conforme Chies (2008), o sistema jurídico da modernidade ainda pode ser classificado como "jurídico-macho-penal", executor prioritário da criminalização, da punição e da dor. Esse sistema necessita resgatar a dignidade de Pandora, mas ainda resiste à "abertura" da caixa e à análise do que, além do universo unicamente masculino, existe na sociedade.

Porém, ser mulher nas prisões implica inúmeras dificuldades, também sentidas pelos homens, contudo, com muito mais intensidade para elas.

A privação de liberdade é a mais óbvia das privações por que passa o preso. Para a mulher, tal situação reveste-se de carac- 
terísticas ainda mais dolorosas já que o rompimento do contato contínuo com seus familiares e, sobretudo, seus filhos, é extremamente difícil de suportar [...] Várias internas são praticamente abandonadas pela família. Visitas, às vezes freqüentes no início, vão aos poucos rareando até serem definitivamente interrompidas. Muito comuns são os casos em que a família custeia inicialmente os honorários do advogado e, após algum tempo, interrompe o pagamento deixando as mulheres entregues à sua própria sorte (LEMGRUBER, 1999, p. 96-97).

Conforme Lemgruber (1999), as relações afetivas que as mulheres apenadas normalmente tinham fragilizam-se, principalmente nos casos de condenações longas. Via de regra, a mulher que vivia com um companheiro experimenta o rompimento da união, e seus filhos ficam sob o cuidado de parentes mais próximos (como avós e tias), e, na ausência desses, ficam abrigados em alguma instituição. Ainda existiram casos em que os companheiros falavam para os filhos que a mãe havia morrido, para que estes não alimentassem esperança de encontros futuros.

De acordo com Olga Espinoza (2004), para falarmos da mulher e de seu envolvimento com o sistema punitivo, devemos partir do pressuposto de que o sistema penal não atende aos propósitos que lhe são inerentes, constituindose como uma instituição eletiva e perversa, que recruta sua "clientela" entre os mais miseráveis.

A imagem da mulher foi construída como sujeito fraco em corpo e inteligência, produto de falhas genéticas - postura na qual se baseia a criminologia positivista quando se ocupa da mulher criminosa. Outra característica que lhe atribuíram foi a inclinação ao mal em face da menor resistência à tentação, além do predomínio da carnalidade em detrimento da espiritualidade. Justificava-se, portanto um patrulhamento mais efetivo pela Igreja e pelo Estado. A ideologia da "tutela", introduzida pelo discurso inquisitorial, estendeu-se aos cristãos-novos, aos indígenas, aos negros, às prostitutas, aos doentes mentais, às crianças e adolescentes, aos velhos, entre outros, tanto para protegê-los quanto para reprimi -los. E deve ser compreendida como o paradigma da colonização e dos inferiores da própria raça (ESPINOZA, 2004, p. 55-56).

Sendo assim:

A mulher presa é vista como transgressora da ordem em dois níveis: a) a ordem da sociedade; b) a ordem da família, abandonando seu papel de mãe e esposa - o papel que the foi destinado. E deve suportar uma dupla repressão: a) a privação de liberdade comum a todos os prisioneiros; b) uma vigilância rígida para "protegê-las contra elas mesmas", o que explica porque a direção de uma prisão de mulheres se sente investida de uma missão moral (SORCIÈRE apud LEMGRUBER, 1999, p. 100). 
Logo, o período de reclusão era pensado com o intuito de educar as mulheres para a reintegração social e de "convertê-las em caridosas beatas" (CHIES, 2008, p. 89), direcionando suas atenções ao lar, aos filhos e à sexualidade voltada para a procriação e para a satisfação do marido.

Essa realidade, muito intensa nos anos 1940 (década de surgimento dos presídios femininos), ainda pode ser observada nos dias atuais, nos quais as mudanças culturais e o controle do Estado apresentam, implicitamente, as tendências à docilização da mulher, ao retorno às atividades domésticas, maquiando, por meio do sistema penal, métodos coercitivos.

Os estudos da criminologia feminista foram muito importantes para o avanço e as conquistas em relação à caracterização de espaço físico (com os presídios femininos) e às políticas carcerárias que tenham como foco a mulher, pois buscam especular e atender às necessidades e aos interesses das mulheres, objetivando transpor os limites até então impostos pela criminologia, a qual se guia por uma perspectiva masculina (ESPINOZA, 2004).

A primeira grande contribuição é dada pela introdução da perspectiva de gênero como instrumento para observar as mulheres no sistema punitivo, ou seja, para entender o sistema (e o cárcere) como construção social que pretende reproduzir as concepções tradicionais sobre a natureza e os papéis femininos e masculinos, segundo instituídos na modernidade. Assim, para tomar conhecimento de como se constrói a feminilidade no sistema penal, devemos extrapolar esse âmbito e estudar as mulheres justificáveis, no mundo das próprias mulheres. Desse modo, seremos levados a compreender "a feminilidade feminina" a partir do questionamento da sociedade e a propor políticas baseadas não na reabilitação das presas, mas na "reforma das relações sociais de sexo e das instituições que as sustêm". Essa proposta, que exprime uma postura favorável às mulheres e apresenta o desvio dela em relação ao status de sujeitos oprimidos na sociedade, não pretende "combater" o "crime" desse grupo, mas a condição de exclusão que as afeta como grupo (ESPINOZA, 2004, p.74-75).

Além disso, segundo Espinoza (2004), esses estudos procuram valorizar os atores como sujeitos, concedendo reconhecimento às vozes e às experiências de vida, entendendo o objeto de pesquisa e todo o contexto do dia a dia do sistema prisional, com foco no viés feminino dessas discussões.

A preocupação em apresentar integralmente o mundo da prisão feminina pode ser entendida como o propósito de dar a conhecer um contexto que, até pouco tempo, só tinha sido pensado em referência ao universo masculino - como um anexo, ou, pior ainda, como um erro. Em virtude dessa constatação, evidenciar as diferenças entre ambos os espaços, descrevendo-os globalmente, adquiriu novo valor e importância (ESPINOZA, 2004, p. 83). 
Quanto ao surgimento das prisões femininas, estas, na maioria das vezes, foram instaladas em conventos, com a finalidade de induzir as mulheres "desviadas" ao retorno do controle, encaixando-as em modelos tradicionais, entendidos de acordo com padrões sexistas (ESPINOZA, 2004).

Conforme Chies (2008, p. 93), a lei que regulamenta o sistema penal brasileiro é uma "lei dos homens, o judiciário dos homens, a justiça dos homens que encarcera as mulheres", proposição corroborada pelo fato de que não existem ressalvas no Direito que assegurem à mulher encarcerada garantias especiais, como o direito à licença-maternidade, no caso de presas gestantes e trabalhadoras. Nessa perspectiva, é válida a observação de Espinoza (2004) de que a legislação brasileira é insuficiente ${ }^{3}$ para abranger a totalidade das necessidades femininas.

\section{Considerações Finais}

O encarceramento feminino vem ampliando-se com o decorrer dos anos, e apesar das conquistas dos grupos feministas, as leis ainda revelam em suas construções um viés sexista. Devido a isso, muitas vezes, a justiça dos homens não se dispõe a compreender e a atender às especificidades do incremento do encarceramento de mulheres e, quando o faz, normalmente cumpre medidas irrisórias em relação às reais demandas do segmento.

Mesmo com as inovações da Constituição Federal de 1988 e outras políticas que abarcam tanto a prisão como as mulheres, as necessidades ainda crescem. Sabendo que as prisões continuarão a existir por muito tempo e que a atenção para estas somente se dá quando existe a possibilidade de quem está dentro dos muros interferir na convivência social dos ditos em liberdade, e observando o agravante dos muitos pontos carentes no que tange às políticas voltada à mulher encarcerada, fica evidente a importância de investigação no assunto, tanto para que existam evoluções no que tange a prisão e para que a visão de uma perspectiva dominantemente masculina seja superada, pois o feminino permeia os ambientes prisionais e por isso precisa ser visto com intensidade.

3 Isso não obstante os avanços da Portaria Interministerial MJ/SPM n ${ }^{\circ}$ 210/2014 - Política Nacional de Atenção às Mulheres em Situação de Privação de Liberdade e Egressas do Sistema Prisional. 


\section{Referências}

BAUMAN, Zygmunt. Globalização: as consequências humanas. Rio de Janeiro: Jorge Zahar, 1999.

BRASIL. Constituição (1988). Constituição da República Federativa do Brasil. Brasília, DF, Senado, 1998.

BUTLER, Judith. Problemas de Gênero: feminismo e subversão da identidade; Trad. Renato Aguiar. 2. ed. Rio de Janeiro: Civilização Brasileira, 2008.

CHIES, Luiz Antônio Bogo. A Questão Penitenciária. Tempo social - Revista de Sociologia da USP, São Paulo, v. 25, n. 1, p.15-36, 2013.

Gênero, criminalização, punição e "sistema de justiça criminal": Um olhar sobre as sobrecargas punitivas e as dominações do masculino. Revista de Estudos Criminais, Porto Alegre, n. 28, p. 81-105, jan./mar., 2008.

DE GIORGI, Alessandro. A miséria governada pela prisão. Rio de Janeiro: Revan, 2006.

ESPINOZA, Olga. A mulher encarcerada em face do poder punitivo. São Paulo: IBCCRIM, 2004.

FOUCAULT, Michel. Vigiar e punir. 28. ed. Petrópolis: Vozes, 2004.

FREIRE, Chistiane Russomano. Prefácio. In: NERY, Tânia Regina Armani. Da ética à poética do ser servidor penitenciário. Porto Alegre: Companhia Rio-Grandense de Artes Gráficas; 2012.

GARLAND, David. A cultura do controle: crime e ordem social na sociedade contemporânea. Tradução de André Nascimento. Rio de Janeiro: Revan, 2008.

LEMGRUBER, Julita. Cemitério dos vivos: análise sociológica de uma prisão de mulheres. 2 ed. Rio de Janeiro: Forense, 1999.

RUSCHE, Georg; KIRCHHEIMER, Otto. Punição e estrutura social. 2. ed. Rio de Janeiro: Revan, 2004.

WACQUANT, Loïc. Punir os pobres: a nova gestão da miséria nos Estados Unidos. 2. ed. Rio de Janeiro: Revan, 2003. 